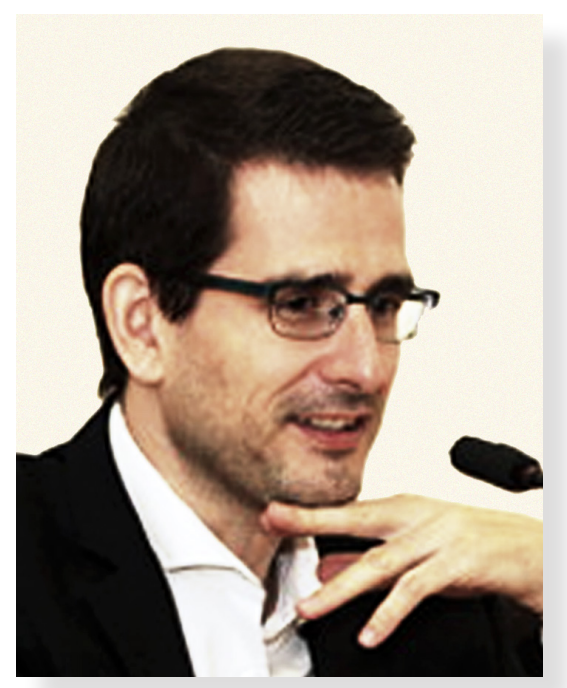

Gonzalo Martín de Marcos"

\title{
La inmediación de los contenidos en los Estudios Generales. Riesgos de los enfoques por competencias
}

\author{
In-mediation of Contents in General Education \\ (Competency Approach Risks)
}

Recibido: 24-04-17 Aprobado: 05-06-17

\section{Resumen}

Este trabajo impugna el papel que los enfoques por competencias hegemónicos han otorgado a los contenidos. El saber hacer los ha instrumentalizado cometiendo un doble error: ha disociado el sujeto del objeto, base fundamental del conocimiento moderno; y ha cosificado la cultura humana, base de los Estudios Generales. A partir del pensamiento de Mijail Bajtín, Edgar Morin y R. M. Hutchins, propongo que deben reubicarse los contenidos, para que recuperen el lugar nuclear que deberían ostentar en la educación general.

\section{Abstract}

This paper refutes the role that hegemonic Competence Approaches have given to the contents. The how to do has made them instrumented by making a double mistake: it has dissociated the subject from the object, the fundamental basis of modern knowledge; and has reified human Culture, the basis of General Studies. From the thought of Mijail Bakhtin, Edgar Morin and R. M. Hutchins, I proposed that contents must been relocated, so that they recover the nuclear place that they should display in general education.

\author{
Palabras clave \\ Contenidos; competencias; Estudios Generales; subjetividad; objetividad
}

\section{Keywords}

Contents; competencies; general Studies; subjectivity; objectivity

\footnotetext{
*Gonzalo Martín de Marcos: Doctor en Literatura Española en Arizona State University (Estados Unidos). Doctor en Filología Hispánica en la Universidad de Valladolid (España). Investigador sobre Literatura Española contemporánea, Teoría de la Argumentación, Estudios de Terrorismo y Estudios Generales. Profesor a tiempo completo del Departamento de Español y del Doctorado en Estudios del Español, en la Pontifica Universidad Madre y Maestra (PUCMM). Director del Departamento de Estudios Generales en el Campus Santo Tomás de Aquino de la PUCMM.
} 


\section{Introducción}

"Los llamados Estudios Generales (Studium generale) tienen una muy larga historia. Sus orígenes se remontan al siglo XII y fueron la base para la creación de las primeras universidades en el Medioevo" (Tubino, 2010, p. 11). Aunque hay concepciones diversas de lo que son los Estudios Generales, todas pretenden arrancar de la concepción que comporta el vocablo adjetivo: generales porque es para todos; generales porque es una educación de validez universal; y generales porque engendra nuevos conocimientos, es decir, cultura (Velez, 2013, pp. 2-3). En particular, entiendo que dos rasgos definen a los Estudios Generales: la sustancia del humanismo y la estructura de la interconexión entre las disciplinas. El humanismo supone que las materias se imparten desde la perspectiva del ser humano; las conexiones impiden que ninguna asignatura esté aislada en su disciplina, sino que establezca relaciones con otras, como una forma de combatir la hiperespecialización.

Este programa debe convivir con el modelo educativo basado en las competencias, por medio del cual ha tratado de solventarse el exceso de academicismo, en el que los estudiantes reproducían y memorizaban pasivamente los contenidos.

El enfoque por competencias-auspiciado por la UNESCO, el FMI, la Unión Europea, el Banco Interamericano de Desarrollo, los Ministerios de cada país, etc.-pretende traer la vida 'real' a las aulas. Pero, ¿qué es la vida real? ¿Quién determina una categoría tan inasible y subjetiva? ¿Acaso la cultura letrada no concierne a la vida real? Las competencias, como señala Bravlasky, consisten en la adquisición de conocimiento a través de la acción, lo cual resultará en una cultura de base sólida que puede ponerse en práctica y utilizarse para explicar qué es lo que está sucediendo. Véase que, según esta definición, se trata de darle una aplicación práctica a los contenidos, lo cual supone la asunción opinable de que todo debe tener un reflejo tangible, pragmático. De todas formas, deja bien sentado que las competencias son el medio, y no al revés.

En este contexto general es ineludible señalar el caso del enfoque complejo de las competencias, desarrollado por Sergio Tobón. Se trata de un enfoque posterior al inicio de las competencias, que se encamina hacia la resolución del problema que el presente artículo observa. Tobón señala que su modelo coexiste con tres modelos más: el conductual, el funcionalista y el constructivista. A estos tres los caracteriza una misma concepción de la competencia, por medio de la cual se han de "resolver dificultades en los procesos laborales profesionales, desde el marco organizacional" (2007, p. 19). El modelo complejo, por el contrario, define así la competencia:

Procesos complejos de pensamiento con idoneidad en determinados contextos, integrando diferentes saberes (saber ser, saber hacer, saber conocer y saber convivir), para realizar actividades y/o resolver problemas con sentido de reto, motivación, flexibilidad, creatividad, comprensión y emprendimiento, dentro de una perspectiva de procesamiento metacognitivo, mejoramiento continuo y compromiso ético, con la meta de contribuir al desarrollo personal, la construcción y afianzamiento del tejido social, la búsqueda continua del desarrollo económico empresarial sostenible y el cuidado y la protección de las especies vivas. (Tobón, 2007, p. 17).

Ser, conocer, convivir, creatividad, comprensión, compromiso ético, desarrollo personal son algunos de los elementos que delatan el afán rehumanizador de este enfoque, frente a los funcionalistas. No cabe duda de que la complejidad subyacente a este enfoque favorece la conciliación con la filosofía de Estudios Generales, pero lamentablemente existe una hegemonía de aquellos otros que potencian el rendimiento eficaz y profesionalizante de los alumnos competentes laboralmente.

El patronazgo empresarial e institucional del que se benefician estos últimos amerita una reflexión crítica de sus fricciones con el humanismo. Además, el enfoque complejo por competencias no acentúa el asunto de los contenidos, sobre los que este trabajo desea hacer un énfasis muy particular. Queda para más adelante un trabajo conjunto para forjar una convivencia simbiótica entre el valiente planteamiento de Tobón y la versión moderna de los Estudios Generales.

Por el momento, y a juicio de quien escribe, son los enfoques empíricos los preeminentes. Aquellos cuyo propósito de base (atiéndase a que no hablo de idea) colide con los principios filosóficos de los Estudios Generales. En referencia a estos, centremos ya el asunto: el saber hacer se ha hipertrofiado hasta el punto de que las competencias funcionalistas son el objetivo supremo al que han de subordinarse los contenidos. Es más, los contenidos acaban convertidos en un medio para que el alumno sea competente. Sin embargo, los contenidos-productos de nuestra cultura-no pueden instrumentalizarse. Los contenidos son selecciones de la cultura humana, y la cultura humana es una extensión del ser humano. No hay disociación entre cultura y ser humano. El ser humano es un yo más su cultura. $\mathrm{Si}$ instrumentalizamos los contenidos, se deduce así, estaremos instrumentalizando al ser humano. 
Presentaremos, entonces, la estructura silogística de un argumento cuyo objetivo es demostrar la tesis de este artículo. Como todo silogismo, expondremos sus premisas y la negación de ambas para negar finalmente la negación de la conclusión a partir de las ideas de Thomas Khun, Edgar Morin, Robert Maynard Hutchins y Mijail Bajtín, con el fin de evidenciar que el empleo de los contenidos como un instrumento para alcanzar las competencias tiene como consecuencia instrumentalizarlos, es decir, convertirlos en instrumentos. En los Estudios Generales, los contenidos que se enseñan son parte del mismo ser humano al que se le enseñan. Los contenidos son saberes fruto de la cultura, y la cultura no es parte accesoria del hombre, sino parte constitutiva de él.

\section{Los contenidos como parte indisociable de la cultura}

Para comenzar, expondremos el argumento y su estructura silogística:

Si las ciencias aportan contenidos objetivos y las humanidades aportan contenidos objetivos, entonces los contenidos pueden usarse (por su carácter de objetos) como un medio externo para hacer competentes a los alumnos.

Como en todo silogismo, si las premisas son falsas, la conclusión es falsa. Negaré primero las dos premisas para concluir la negación de la última afirmación, que es en realidad la tesis de este artículo: los contenidos no pueden ser simples medios para hacer competentes a los alumnos, menos aún en el contexto de los Estudios Generales, porque los contenidos son secciones de la cultura de la que los alumnos mismos forman parte indisociable. No ya en términos prácticos o técnicos, pues las competencias quedarían en el aire, sin sustento, sino en términos éticos.

\section{Negación de la premisa mayor: las ciencias empíricas no aportan contenidos objetivos}

Existe un complejo en las ciencias empíricas, según el cual estas se creen, y así son tenidas, por objetivas. A saber, que hay un distanciamiento entre el yo investigador, descubridor y productor de conocimientos científicos y estos conocimientos científicos. En otras palabras, que el científico no se involucra con su objeto de estudio y este queda intacto, virgen, como un hecho incontrovertible. Las leyes científicas, por tanto, son un reflejo fiel de la realidad. Sin embargo, esto no es así, o al menos, no es tan claro.

El primero en sospechar de la objetividad de las ciencias fue el filósofo de la ciencia Thomas Khun, doctor en
Física por la Universidad de Harvard. Khun estaba tomando un curso de Historia de la ciencia cuando tuvo una epifanía. Se dio cuenta de que las revoluciones científicas estaban determinadas por el contexto cultural en que ocurrían. La evolución de las ciencias seguía un ciclo. Primero sobrevenía una crisis que alteraba el paradigma del momento. La crisis traía una revolución científica que sustituía al paradigma anterior e instauraba su propio paradigma. Tras esto venía un período de estabilidad que una nueva crisis rompía. Y así sucesivamente (Khun, 1971). Para los autores de la segunda revolución, los científicos de la primera estaban equivocados, pero Khun dice que para entender el valor científico de una revolución hay que situarse en el momento histórico que la determinó. Ello supone que la ciencia está determinada por la historia. Y si la Historia es el conjunto de los hechos de la humanidad, la ciencia es inseparable de los hechos de la humanidad. Es inseparable de la cultura, la sociedad, la economía. Inseparable de la Filosofía, de las revoluciones populares, de los sistemas de distribución de tierras, etc.

Edgar Morin, padre del pensamiento complejo, tiene una opinión muy semejante a la de Khun sobre la objetividad de las ciencias. Edgar Morin es un referente muy citado en los Estudios Generales, porque su idea del pensamiento complejo contribuye en gran parte a la interdisciplinariedad. Para Morin,

[e]l conocimiento científico no es el reflejo de las leyes de la naturaleza. Lleva en sí un universo de teorías, de ideas, de paradigmas (...) que nos remite al enraizamiento cultural, social e históricos de estas teorías. Las teorías científicas surgen de los espíritus humanos en el seno de una cultura hic et nunc. (1984, p. 42).

Junto a esta aceptación de la conexión de las ciencias con la cultura, Morin postula una reconciliación entre el sujeto y el objeto. Es decir, reunir al investigador con lo investigado. Aquella distancia pulcra que el científico dice mantener con la naturaleza, no puede ser tal. No es tal, según el principio de Heissenberg, según el cual nuestra propia observación de los hechos altera los hechos mismos. Es decir, que nosotros no podemos separarnos de lo que estudiamos. Es decir, que no hay objetividad. Es decir, que "el campo real del conocimiento no es el objeto puro (...), sino el objeto visto, percibido, y coproducido por nosotros. El objeto del conocimiento no es el mundo, sino la comunidad nosotros-mundo, porque nuestro mundo forma parte de nuestra visión del mundo, la cual forma parte de nuestro mundo" (1984, p. 108).

Khun y Morin, tanto como otros filósofos de la ciencia no citados aquí (Popper, Feyerabend y otros), advierten del error de atribuir a las ciencias una objetividad 
inexpugnable. Las ciencias empíricas se han rodeado de un halo de objetividad, irrefutabilidad y precisión del que debemos, como poco, sospechar, si observamos su evolución histórica. Esto significa que los contenidos científicos no pueden explicarse como realidades inopinables ajenas a la cultura humana. Significa que si así lo hacemos estaremos sajando una realidad dual, la que une el sujeto al objeto.

En el contexto de la universidad contemporánea, "las ciencias duras se hacen blandas y las ciencias blandas pretenden ser duras" (Bravo León, 2016).

\section{Negación de la premisa menor: las ciencias humanas no aportan contenidos objetivos}

Parece más fácil negar que las ciencias humanas sean objetivas, aunque sólo sea por la adjetivación que llevan, humanas. Pero la instrumentalización de los saberes que han experimentado las universidades desde el siglo XVIII ha producido una asimilación de las ciencias humanas a las ciencias empíricas, cuya supremacía ha sido creciente. En otras palabras, las ciencias humanas han querido parecerse a las ciencias empíricas bajo el complejo de que en lo más objetivo hay más rigor, y bajo el prejuicio de que, si las ciencias empíricas son objetivas y tienen más rigor, habrá que asemejarse a ellas para obtener su mismo respeto, el respeto que les ha granjeado el racionalismo.

Para empezar, ya he tratado de impugnar la objetividad de las ciencias empíricas en el apartado anterior. Pero tal impugnación, de verificarse, no cambia la tendencia objetivante de las ciencias del espíritu. Valga un ejemplo de mi disciplina de especialización, los Estudios Literarios. A comienzos del siglo XX, la escuela del Formalismo ruso comenzó una sistematización de los Estudios Literarios que, más tarde, alcanzó a la Lingüística y, con Saussurre, dio pie a la Lingüística moderna. Estos avances, de indudable valor, se han hipertrofiado hasta el punto de que los métodos de análisis se han impuesto a las realidades culturales. Un ejemplo: ha importado más el método de análisis de una novela, que Los miserables, de Victor Hugo.

Este proceso, imparable, explica parte de la reacción de Robert Maynard Hutchins a mediados del siglo XX. Hutchins fue un pedagogo y pensador que ejerció de rector de la Universidad de Chicago. Se le considera uno de los creadores de los modernos Estudios Generales. En su libro The University of Utopia señala: "[l]iberal education was associated in the public mind with a preindustrial, pre-scientific, pre-democratic era. It was an anachronism, and an aristocratic anachronism" (1964, p. 13). Las artes liberales, aquellas que en la Edad Media solo cursaban los hombres libres, recibieron por esta causa el estigma del elitismo, y también de un elitismo arcaico, obsoleto, en un tiempo en que las ciencias bastan al ser humano. Este prejuicio explica aquel afán por parecerse a las mismas disciplinas que las denostaban. Pues bien, en este contexto, las humanidades se han violentado para objetivar tanto su objeto de estudio, como su metodología.

Pero las humanidades, tanto o más que las ciencias empíricas, el objeto de estudio ha de ser la alianza yomundo, no el mundo; la alianza yo-realidad, en el caso de la ontología, no la realidad a secas; la alianza yorevoluciones, en el caso de la historia, no las revoluciones aisladas. Esta disociación, consabida en las ciencias empíricas, se nos ha deslizado subrepticiamente en la academia hasta el punto de imponernos ser objetivos en la Historia, en las Artes. Las consecuencias de ello son enormes, porque afectan a la dimensión ética de la relación del ser humano con la cultura.

Mijail Bajtín ha reflexionado sobre esto en Hacia una filosofía del acto ético. Para Bajtín, la moral de la vida diaria no se interpenetra con la moral de la obra artística. Hay un hiato entre el mundo de la cultura y el mundo de la vida, "[q] ue aparecen incomunicados entre sí, no existe un principio para incluir el mundo significante de la teoría y de la cultura teorizada al único y singular acontecimiento del ser en la vida" (1997, p. 28). Pero el acto ético debe ser un acto en su totalidad (1997, p.7), no puede haber tal escisión entre lo que llama la responsabilidad especializada (la de las obras) y la responsabilidad moral (la de la vida) (1997, p. 8). Separar el yo de su objeto, abrir más la brecha que en las humanidades practicaron quienes querían parecerse al cartesianismo de las ciencias empíricas, produce un desgarro ético.

\section{Negación de la conclusión: los contenidos de Estudios Generales no deben ser un medio para la adquisición de las competencias}

Dice la lógica de un silogismo que la negación de las premisas, mayor y menor, conduce a la negación automática de la conclusión. Pero la lógica formal (artificial) se guía por leyes que no funcionan en lógica argumental (natural), de modo que ha de aportarse un discurso extra que refute tal afirmación. Recuérdese que la conclusión que pretendo refutar es la siguiente: los contenidos pueden usarse como un medio externo para hacer competentes a los alumnos.

La idea de que los contenidos funcionen como medio para lograr las competencias descansa en el concepto de instrumentalidad. Un instrumento es aquello que sirve para lograr algo distinto. Es decir, que el instrumento sólo posee valor subsidiario, en tanto herramienta para otro fin superior. El instrumento no tiene, por sí mismo, ningún valor. Este concepto, transpuesto a los ámbitos 
culturales y extendido hasta constituir toda una corriente es la base del Utilitarismo. Para los utilitaristas, el fin justifica los medios, porque sólo importan los efectos. El utilitarista observa con imparcialidad cualquier proceso con tal que los resultados sean beneficiosos. El utilitarista mediatiza la realidad para obtener un rendimiento. Si aplicamos esto al enfoque por competencias, el empleo de los contenidos como un instrumento para alcanzar las competencias tiene como consecuencia instrumentalizar aquellos, convertirlos en instrumentos.

Pero adviértase que los contenidos son saberes fruto de la cultura, y que la cultura no es parte accesoria del hombre, sino parte constitutiva de él. El ser humano se constituye en ciudadano en su unión con la cultura que él ha generado. Si yo instrumentalizo la cultura, estoy instrumentalizando una parte del ser humano, lo cual supone una flagrante deshumanización de una parte de nosotros. Al emplear los contenidos como medios estamos cosificando al ciudadano. No puede hacerse competente al ciudadano instrumentalizando una parte del propio ciudadano. El trasfondo tecnificante e instrumental de las competencias, asociado a la alarmante devaluación de los contenidos, han sido advertido por muchos: Col y Martín (2006), Wheelahan (2007), Jones \& Moore (2008), pero deseo citar aquí el rescate de la tríada cognoscitiva clásica que realizan Angulo y Redón (2011, p. 296):

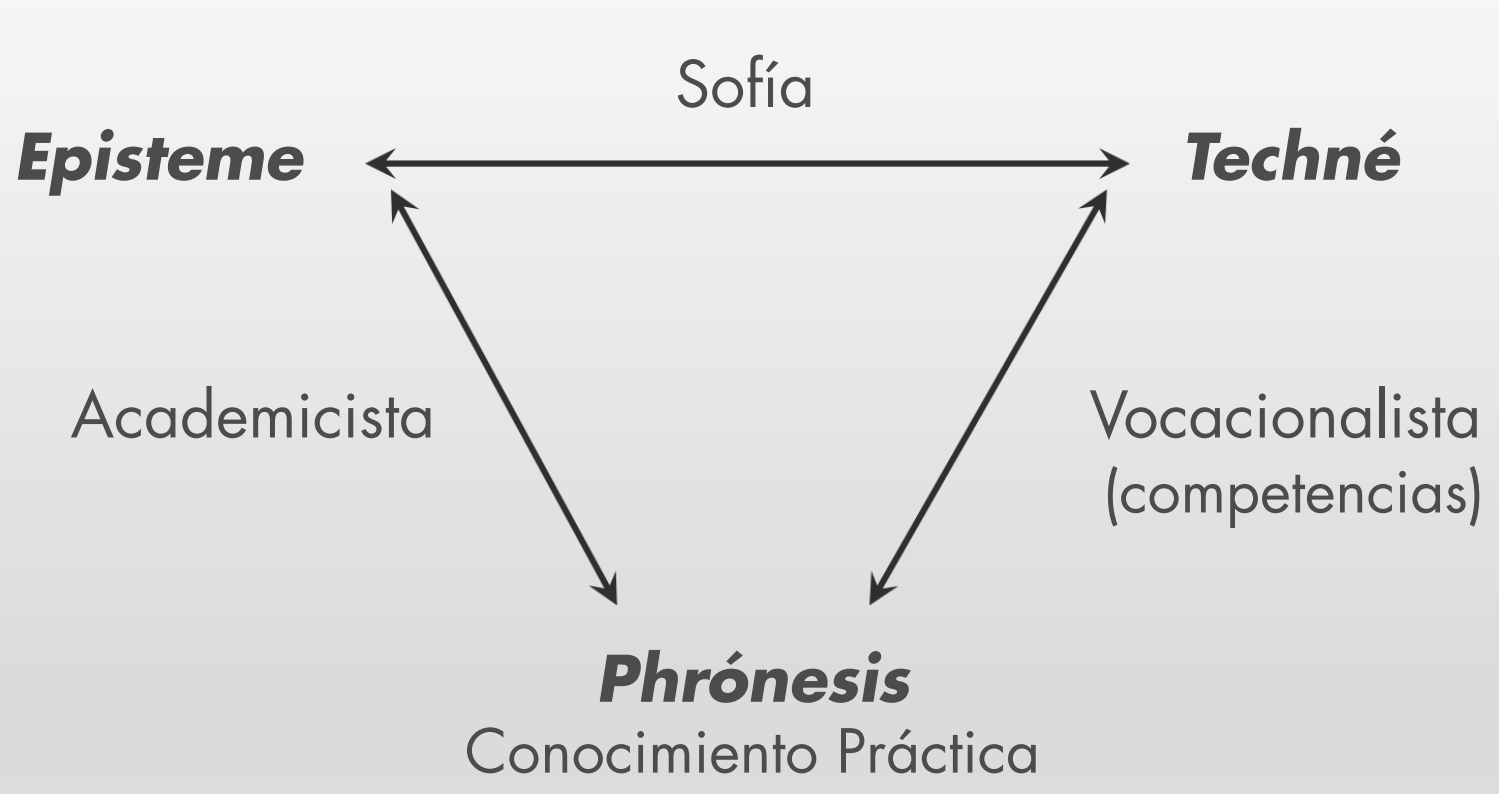

En este diálogo entre habilidades, los conocimientos y los conocimientos aplicados, el modelo por competencias ha hipertrofiado la techné hasta provocar el "[e]nmascaramiento del debate epistemológico y político sobre los contenidos" (Angulo \& Redón, 2011, p. 295). Sin contenidos no hay nada; sin contenidos nos abocamos a una educación mercantilizada que necesita egresados competentes para la producción de la rentabilidad. Es más, sin contenidos, sólo tendríamos competencias, aún más, competencias exclusivamente técnicas, pues, como señala D'Amore, las bases cognoscitivas de una competencia son necesariamente disciplinarias (2005).

Esta contradicción se agrava en el ámbito de los Estudios Generales. Primero, porque los Estudios Generales obtienen su sustancia del humanismo, corriente ideológica y cultural que, originada en la Europa del Renacimiento, sitúa en el centro al ser humano. Aquel antropocentrismo, con todas las matizaciones de la posmodernidad- la empatía con la naturaleza, la crítica al racionalismo, la descentralización cultural, etc.,-— supone en la actualidad que no puede haber separación entre mi persona y la cultura, entre mi persona y la naturaleza. Por eso, no puede haber objetividad en el humanismo. El humanismo ha de combatir el fanatismo de la objetividad y exaltar la libertad de la subjetividad. Por ello, al negar las premisas, refuté la objetividad de las ciencias empíricas y de las ciencias humanas.

En los Estudios Generales los contenidos que se enseñan son parte del mismo ser humano al que se le enseñan. Separarlos de las competencias, cuyo modelo es deshumanizadoramente tecnificante, es desconocer el proceso de constitución de la cultura, que no es sino la expresión de los pueblos. Como señala Quintanilla, a propósito 
de las competencias en los Estudios Generales, aquellas deben basarse sobre los conocimientos que aportan los contenidos (2015, pp. 3 y 10). Y estos contenidos, que formarán los conocimientos, "[d]eben ser fundamentales, estructurados, y consistentes entre sí, para dar lugar a la posterior incorporación de nuevos conocimientos (...) Sin embargo, estos cimientos también deben ser suficientemente flexibles para que el alumno pueda revisarlos continuamente, si esto lo amerita" (2015, p. 9).

Es decir, que, aunque los contenidos no sean inmutables, constituyen la base, no una mediación ni un instrumento. En segundo lugar, los contenidos de las asignaturas de Estudios Generales no pueden ser de carácter propedéutico. Ello quiere decir que los contenidos no pueden servir para preparar al estudiante para otras asignaturas o fases posteriores de otras carreras.

No quiero decir que el enfoque por competencias sea propedéutico (al menos en su declaración formal: pues en su trasfondo quiere preparar profesionales, en el sentido más peyorativo de la palabra). Lo que digo es que al subrayar esas capacidades como bien supremo, los contenidos se devalúan hasta convertirse en un instrumento de formación. E instrumentalizar los contenidos-que proceden de nuestra cultura humana-es, insisto, instrumentalizar a los ciudadanos.

\section{Referencias}

Angulo, F. \& y Redón Pandoja, S. (2011). "Competencias y contenidos: cada uno en su sitio en la formación docente". Estudios pedagógicos, vol. 37, (12). 281299.

Bajtín, M. (1997). Hacia una filosofía del acto ético. Madrid: Anthropos.

Bravlasky, C. Enfoque por competencias. http://www.ibe. unesco.org/es/temas/enfoque-por-competencias

Bravo León, F. (2016). "A propósito de la universidad de Estudios Generales". VIII Simposio Internacional de Estudios Generales. Universidad Santo Tomás de Aquino. Bogotá. 17 de noviembre de 2016.

Col, C. y Martín, E. (2006). Vigencia del debate curricular. Aprendizajes básicos, competencias y estándares. II reunión del Comité Intergubernamental del Proyecto Regional de Educación para América Latina y el Caribe (PRELAC). Santiago de Chile. 11-13 de mayo de 2006. Documento no publicado. URL: http:!!www.ub.edu/gintrie (21/09/10).

D'Amore, B. (2005). "Contenidos, conocimientos, competencias, capacidades, núcleos fundacionales: la complejidad de la educación y de la construcción del saber", Enunciación, vol. 10 (1), 54-58.

Jones, L. \& Moore, R. (2008). "La apropiación del significado de competencia: el movimiento de la competencia, la Nueva Derecha y el proyecto de 'cambio cultural", Profesorado. Revista de currículum y formación del profesorado, 12.3 (2008) (http://www.ugr.es/local/recfpro/rev123ART7.pdf) (consultado el 24/11/16).

Hutchins, R. M. (1964). The University of Utopia. Chicago, London: The University of Chicago Press.

Khun, T. (2004). La estructura de las revoluciones científicas. México: FCE.

Morin, E. (2011). Introducción al pensamiento complejo. Barcelona: Gedisa.

Morin, E. (1984). Ciencia con conciencia. Barcelona. Anthropos.

Quintanilla, P. (2015). "Conocimientos, competencias y habilidades. Cómo integrarlas, enseñarlas y formarlas en los Estudios Generales". Documentos, vol. 22, pp.3-22.

Tobón, S. (2007). "El enfoque complejo de las competencias y el diseño curricular por ciclos propedéuticos". Acción pedagógica, vol. 16, pp. 14-28.

Tubino, F. (2010). "La concepción humanista de los Estudios Generales: tareas pendientes". Cuaderno de pedagogía universitaria, vol. 14, pp. 11-16.

Vélez, W. (2013). "Educación general: Definiciones, evolución, paradigmas epistemológicos y futuro". Documentos, vol. 20, 1-16.

Wheelahan, L. (2007). "How competency-based training locks the working class out of powerful knowledge: a modified Bernsteinian analysis". British Journal of Sociology of Education, Vol. 28.5 (2007), 637-651. 